\title{
ESTUDIOS DE MERCADO: EL CASO DE LA MADERA DE CANELO EN ESTADOS UNIDOS Y EUROPA
}

\author{
Jorge Cabrera Perramón (1)
}

\section{RESUMEN}

El trabajo se enmarca dentro del proyecto "Desarrollo de Aplicaciones Industriales no Pulpables de Renovales de Canelo", adjudicado por CORFO al Instituto Forestal, (INFOR) en 2002. El estudio de mercado conforma la base para el desarrollo posterior del proyecto, particularmente en sus fases de tecnología industrial y silvicola.

El objetivo central es investigar las opciones de mercado de la madera de canelo en Estados Unidos y Europa, con el fin de identificar lineas con mayor capacidad competitiva, empresas importadoras con interés real por comprar y definir las condiciones técnicas y comerciales necesarias para abordarlos.

El plan de trabajo consistió en recopilar, procesar y analizar información de mercado obtenida de fuentes secundarias y primarias. Las entrevistas se acompañaron de muestras de madera y un folleto promocional. Se abarcó cuatro Estados de Los EEUU y tres paises de Europa.

En general, se estimó que el canelo es estéticamente muy bueno, es una madera algo liviana y no muy dura, cuyas principales aplicaciones son para muebles y molduras especiales, en las que la apariencia juega un rol determinante.

Los precios referenciales que podrian lograrse para canelo son bastante superiores a los del mercado chileno, superiores a las coniferas y bastante cercanos a especies como abedul, aliso, acer y haya europea.

El estudio reúne una gran información sobre detalles y requisitos comerciales, recomendaciones estratégicas, datos de precios, directorios de empresas con conocimiento de la madera de canelo e interesados especificos.

La conclusión final es que la madera de canelo, efectivamente, puede ser exportada en forma competitiva a estas regiones, de modo que el énfasis futuro es preparar una oferta sostenible y de calidad.

Palabras clave: Mercado, canelo, madera nativa, EE.UU, Europa.

(1) Ingeniero Forestal, Mg (e) Economia Agraria, Dr. (c) Ingeniería Ciencias Forestales. Instituto Forestal. jcabrera@infor.cl 


\section{SUMMARY}

The current Market Analysis performed in the context of the INFOR's Project "Desarrollo de Aplicaciones Industriales no Pulpables de Renovales de Canelo" funded by the Corporación de Fomento de la Producción (CORFO), constitutes the necessary basic step for the future technological and industrial development of

\section{Canelo species.}

The aim of the study is to explore the several market alternatives for three main wood products coming from Canelo in the USA and European countries. Main issue here is the identification of product main lines which involve the best competitive characteristics. Additionally, the identification of importer companies interested in these main lines requesting for particular technological and trade conditions, allowing these products access to the market.

The methodological approach involved market scrutinizing and testing searching at primary and secondary industry level. A set of personal interviews and showing samples of the wood promoted material was devised besides the publishing of a special promotional and informative leaflet. Four states of USA and three European countries were inspected.

Major outcomes of the study was that Canelo wood material is aesthetically attractive, although it seems a slightly light in weight and a kind of softwood. As main industrial applications given their aesthetic characteristics, furniture and moulding products were detected as relevant for this species.

This study compiles an important amount of data and information regarding the trade requirements, some strategic recommendations, price information, and a listing of relevant and really interested companies.

As a final conclusion the Canelo's wood material has a real and competitive chance for exportation to the analyzed market. The main issue is now how to maintain the market demand in a sustainable manner and keeping or improving the required level of the wood material quality.

Key words: Market, Canelo, native wood, USA, Europe. 


\section{INTRODUCCION}

Los estudios de mercado constituyen una base crucial de información que permite conocer los ingresos que efectivamente pudieran generarse de alguna actividad productiva $y$, por tanto, son la clave para decidir sobre las inversiones productivas. Este concepto ha sido introducido en el campo de los proyectos de investigación en el sentido que, primero se determina si el producto es aceptado en el mercado, y recién entonces se decide si se deben realizar las investigaciones necesarias en el campo de las tecnologias de transformación y de los cultivos, según corresponda.

Como parte del Proyecto FDI-CORFO "Desarrollo de Aplicaciones Industriales no Pulpables de la Madera de Renovales de Canelo", se realizó un estudio de mercado para madera de canelo en Europa y Estados Unidos, tema que se aborda en el presente articulo.

Este informe está estructurado con la presentación de los objetivos y aspectos metodológicos, para posteriormente entregar los resultados y conclusiones, en forma separada para cada región estudiada.

El estudio de Mercado fue desarrollado por la consultora Gryphon Resource Consultants Ltd, representada por los Srs Alfonso Casasempere y David Cartwrigh, y por el consultor Paolo Gardino, mediante un subcontrato diseñado, supervisado y coordinado por el autor.

\section{OBJETIVO}

El objetivo general del proyecto es generar y asociar información precompetitiva, sobre aspectos tecnológicos de la madera de canelo y productos de alto valor, con información económica y de mercado, originando una plataforma de información total y una propuesta de desarrollo sostenible de mediano y largo plazo para el recurso renovales de canelo.

El estudio especifico de demanda externa, en términos generales, persigue desarrollar una investigación tecnológica con análisis y pruebas de productos, capaz de generar información técnico-comercial de fuente primaria, para establecer la factibilidad y potencial exportador de productos fabricados con madera de canelo. Más específicamente, se trata de determinar las verdaderas posibilidades para colocar madera de canelo en condiciones competitivas de calidad, precio y entregas.

\section{METODOLOGIA}

Las regiones en estudio son Europa y Estados Unidos de Norteamérica. La selección de paises y Estados se basó en un análisis de ranking de concentración de los mayores importadores y consumidores de madera latifoliada y del presupuesto disponible.

El plan de trabajo consistió en recopilar, procesar y analizar información de mercado obtenida mediante fuentes secundarias y fuentes directas, en las que se efectuó pruebas de mercado. Las entrevistas fueron acompañadas de la entrega de muestras de madera y un 
folleto promocional. Las entrevistas personales se fueron efectuadas cronológicamente en cuatro Estados de USA; Washington, California, Texas y Carolina del Norte, y en Alemania, Italia, Reino Unido y España, en Europa. Se analizó oportunidades para madera aserrada y piezas especiales para interiores, molduras decorativas, molduras pintadas, tableros de madera y productos especiales.

Se definió cuatro categorias de producto para identificar oportunidades de colocación. Estas son:

- Madera aserrada y piezas especiales para interiores, gabinetes y muebles.

- Molduras decorativas especiales, incluyendo pasamanos, marcos para cuadros, piezas, puertas pequeñas, partes para cajas, y otras piezas de pequeñas dimensiones.

- Tableros contrachapados o enlistonados

- Productos especiales, incluyendo marcos para pizarrón, piezas para puertas de seguridad infantil, piezas torneadas, mangos de escoba, tarugos y estantes.

Con el fin de presentar el producto a estudiar se definió y diseñó dos medios de promoción comercial, un folleto introductivo (en castellano e inglés) y muestras de los productos.

El folleto, de alta calidad y en colores, incluye fotos de la madera y sus productos, detalla las propiedades físico - mecánicas de la madera, bondades y usos, cuantifica la oferta actual y futura e identifica el contacto en Chile.

Las muestras de madera se fueron definidas por tipo de producto, dimensiones y calidades. El conjunto se basó en madera seca en horno, tablas cepilladas, varios tipos de molduras y tableros con finger joint y laminados de canto. Todos en dimensiones pequeñas. Estas fueron presentadas a las empresas elegidas en las regiones seleccionadas.

Se preparó un formulario flexible, tipo pauta, con preguntas que permiten homogenizar las respuestas y su posterior tabulado. El tema cubre un ámbito general que describe con estadisticas oficiales, el mercado de la madera y el valor del comercio exterior. con énfasis en el mercado de las maderas latifoliadas, excluyendo el mercado de la pulpa, papel y tableros aglomerados. En un marco específico, el estudio identifica precios referenciales para productos seleccionados, y las condiciones técnicas y comerciales necesarias para entrar al mercado.

A partir de un análisis previo de la distribución y utilizando directorios empresariales y contactos, se preparó una lista de empresas, importadores, distribuidores y usuarios directos a quienes contactar y encuestar. Se cuidó que esta lista fuese representativa y, además, que asegurara una adecuada cobertura del sector. 
Se seleccionó un conjunto amplio de empresas, sobre 200, y por teléfono o por correo electrónico se las contactó para invitarlas a participar en la prospección de la madera de canelo. Treinta empresas fueron contactadas directamente, otra cantidad similar recibió las muestras de productos y fueron encuestadas telefónicamente.

Finalmente, se analizó y tabuló la información de mercado obtenida, tanto de fuente primaria como secundaria, y con estos resultados se estructuró las conclusiones y recomendaciones del estudio.

Operacionalmente, INFOR por medio de una licitación internacional, contrató a dos empresas consultoras, una de cada región de estudio, para lograr mayor eficacia y mejor aplicación del presupuesto. Investigadores de INFOR participaron activamente en el diseño de la investigación y en la supervisión de cada actividad del proyecto.

\section{RESULTADOS}

\section{Mercado en Estados Unidos}

- El Mercado Total de Madera

Estados Unidos es el mayor productor y consumidor de productos de madera en el mundo. También es el mayor importador y el segundo mayor exportador de productos forestales. En términos de la industria representa el mayor mercado potencial para la madera de canelo en el mundo (Cuadro $N^{\circ} 1$ ).

El mercado total de la madera (consumo aparente en construcción y otros usos) en EEUU alcanzó a 229 millones de $\mathrm{m}^{3}$ en 2001. La madera aserrada representó un consumo de 118 millones de $\mathrm{m}^{3}$ al año, mientras que la madera terciada registró casi 18 millones de $\mathrm{m}^{3}$. EEUU importa productos forestales (incluyendo madera, tableros, celulosa y papel) por más de US\$ 24 mil millones por año.

Las importaciones de madera aserrada de especies no coniferas (mayoritariamente latifoliadas o duras) alcanzaron a un valor de US\$ 462 millones en 2001 y las de madera terciada a US\$ 868 millones. Estas cifras y las anteriores corroboran el enorme tamaño del mercado de la madera en EEUU y enmarcan fuertes posibilidades para una colocación futura de madera de canelo de Chile. 


\section{Cuadro $\mathrm{N}^{\circ} 1$}

PRODUCCION, EXPORTACION, IMPORTACION Y CONSUMO APARENTE TOTAL DE MADERA EN EEUU 1997 - 2001 (millones $\mathrm{m}^{3}$ )

\begin{tabular}{|c|c|c|c|c|c|}
\hline & 1997 & 1998 & 1999 & 2000 & 2001 \\
\hline \multicolumn{6}{|l|}{ Producción } \\
\hline Madera Aserrada & 111,4 & 89.0 & 92.6 & 91,1 & 87.3 \\
\hline Hojas de Chapa & 0,1 & 0,1 & 0,1 & 0,1 & 0.1 \\
\hline Madera Terciada & 17.5 & 17.5 & 17.6 & 17,3 & 16.4 \\
\hline MDF & 2.4 & 2.5 & 2,5 & 2,5 & 2.5 \\
\hline Tableros de Madera & 40,1 & 42.6 & 45,6 & 45,5 & 44,1 \\
\hline Tableros de Particulas & 16,3 & 18,1 & 21,0 & 21,2 & 20,8 \\
\hline Total & 187,8 & 169,8 & 179.4 & 177,7 & 171,2 \\
\hline \multicolumn{6}{|l|}{ Importación } \\
\hline Madera Aserrada & 43.7 & 32.7 & 33.8 & $34 . .4$ & 35.2 \\
\hline Hojas de Chapa & 0,7 & 0,5 & 0.4 & 0,4 & 0.4 \\
\hline Madera Terciada & 1.9 & 2.0 & 2.5 & 2.4 & 2.7 \\
\hline MDF & 0.4 & 0.6 & 0,9 & 2.0 & 2.1 \\
\hline Tableros de Madera & 9,3 & 10,7 & 12.2 & 14,3 & 15.5 \\
\hline Tableros de Particulas & 5,8 & 7.2 & 7.9 & 8,9 & 9.7 \\
\hline Total & 61,8 & 53,7 & 57,7 & 62,4 & 65,6 \\
\hline \multicolumn{6}{|l|}{ Exportacion } \\
\hline Madera Aserrada & 7.0 & 4.6 & 5,1 & 5,1 & 4.2 \\
\hline Hojas de Chapa & 0.7 & 0.6 & 0,3 & 0.3 & 0.3 \\
\hline Madera Terciada & 1.6 & 0,8 & 0,7 & 0,7 & 0.5 \\
\hline MDF & 0.1 & 0.2 & 0.2 & 0,2 & 0.2 \\
\hline Tableros de Madera & 3.1 & 2.5 & 2.2 & 2.2 & 1.9 \\
\hline Tableros de Particulas & 0,4 & 0.6 & 0,6 & 0.6 & 0.6 \\
\hline Total & 12,9 & 9,3 & 9,1 & 9,1 & 7,7 \\
\hline \multicolumn{6}{|l|}{ Consumo Aparente } \\
\hline Madera Aserrada & 148,1 & 117,1 & 121,2 & 120,3 & 118,5 \\
\hline Hojas de Chapa & 0.1 & 0.0 & 0.2 & 0.2 & 0.2 \\
\hline Madera Terciada & 17.8 & 18.6 & 19.3 & 19.0 & 18.6 \\
\hline MDF & 2.6 & 29 & 3,2 & 4.3 & 4.4 \\
\hline Otros Tableros de Madera & 46,2 & 50.8 & 55,7 & 57,7 & 57.7 \\
\hline Tableros de Particulas & 21.8 & 24.6 & 28.3 & 29.4 & 29.9 \\
\hline Total & 236,6 & 214,1 & 227,9 & 230,9 & 229,3 \\
\hline
\end{tabular}

(Fuente FAO. 2000) (cofras con aproximacion decimal) 


\section{- El Mercado de la Madera para la Construcción}

En Estados Unidos, el consumo de madera para la construcción se estima en alrededor de 170 millones de $\mathrm{m}^{3}$. La distribución del consumo por uso final es de $43 \%$ en residencias nuevas, $32 \%$ en reparación y renovación, $6 \%$ en usos no residenciales y $19 \%$ en uso industrial

En 1998, el valor de la construcción en los EEUU alcanzó US\$ 665,4 mil millones. De este total el sector de la construcción habitacional representó un $44 \%$. La construcción de viviendas es el sector que más consume productos de madera. En 1999, por primera vez en la historia del país, el número de viviendas construidas superó los 2 millones de unidades. También se ha incrementado la superficie promedio por unidad. Otro cambio es que en 1998 sólo $37 \%$ de las viviendas fueron construidas in situ y el $44 \%$ usaron componentes de paneles y modulares construidos en fábrica.

\section{- Productos de Valor Agregado}

El sector de la construcción de viviendas es un importante consumidor de una variada gama de productos fabricados de madera. Sin entrar en mayor detalle, es importante notar que la importación de muchos de estos productos ha experimentado un fuerte incremento en la última década, resultado de la apreciación del dólar.

La industria nacional que fabrica estos productos continúa utilizando un volumen significativo de productos primarios tanto de origen interno como importado.

\section{- El Sistema de Distribución de Madera en Estados Unidos}

Durante los últimos años ha habido un cambio significativo en la forma de comercializar productos primarios sólidos de madera. El cambio ha sido implementado por las cadenas de establecimientos como Home Depot, Lowes y otros que han desarrollado un poder comprador muy significativo. Ellos han logrado eliminar los intermediarios y compran productos primarios directamente de los productores primarios.

Al tratarse de productos primarios importados, el intermediario tiende jugar un rol mucho más significativo. El importador, en representación del usuario doméstico, identifica y califica productores o exportadores extranjeros capaces de entregar los productos requeridos por uno o más clientes en las condiciones que éste especifica. Estos productos deben reunir las condiciones de secado, calidad, dimensiones, terminación, volúmenes requeridos, entregas periódicas y regulares, empaque, transporte y lugar de entrega especificadas por el importador. El importador, como agente del usuario o como comprador directo, es responsable por el control de estas variables.

En términos del exportador chileno, la identificación de un importador con base en EEUU es el primer paso a tomar en el proceso exportador. 
Con el fin de identificar las mejores firmas a ser encuestadas, inicialmente se contactó a más de 150 empresas. La comunicación se estableció por fax, teléfono y correo electrónico con 43 de estas empresas.

Como resultado de las conversaciones sostenidas durante la primera selección de empresas y tomando en cuenta el deseo de incluir representantes de todos los sectores del sistema de distribución y fabricación de productos de la madera (incluyendo un representante del sector de venta al detalle), se visitó una empresa en el Estado de Washington, once en California, cuatro en Texas y cuatro en Carolina del Norte.

La información y datos detallados obtenidos durante las entrevistas, fue ingresada a una base de datos la cual está disponible en INFOR. En Apéndice $N^{\circ} 1$ se presenta un resumen de los resultados más sobresalientes de las encuestas realizadas, clasificados por variable comercial de acuerdo a las pautas utilizadaS.

\section{Mercado de Europa}

Europa es un mercado netamente exportador de madera de coniferas, pero importador de madera latifoliada (sobre todo de África y del Sudeste Asiático).

Es necesario recordar que Europa no es un mercado carente de madera doméstica. Al contrario, el continente europeo produce grandes cantidades de madera para exportación.

\section{Cuadro $\mathrm{N}^{\circ} 2$ \\ PRODUCCION, IMPORTACION Y EXPORTACION EUROPA}

\begin{tabular}{|l|c|c|}
\hline \multicolumn{1}{|c|}{2001} & $\begin{array}{c}\text { Madera aserrada coniferas } \\
\text { (millones m') }\end{array}$ & $\begin{array}{c}\text { Madera aserrada latifoliadas } \\
\text { (miliones m }\end{array}$ \\
\hline Europa producción & 92 & 16 \\
\hline Europa importación & 37 & 9 \\
\hline Europa exportación & 40 & 5 \\
\hline Consumo & 89 & 20 \\
\hline
\end{tabular}

(Fuente. FAO. 2002)

En Europa, las importaciones de tablones de madera latifoliada han subido constantemente desde 1996 hasta 2001, pasando de 5,5 millones de de metros cúbicos a casi 10 millones (FAO, 2002). En 2003 se esperaba una caida leve de las importaciones, pero en general la demanda queda alta (Gardino, 2003). Los sectores de más consumo son los del mueble, los del embalaje y los de los pisos de madera.

Italia es sin duda el mayor importador de tablones de madera latifoliada, gracias a su considerable industria del mueble.

En el pasado, Italia ha representado hasta el $25 \%$ de las importaciones europeas. La crisis actual de los gastos y, en particular, en la industria del mueble, ha reducido las importaciones, pero la tendencia futura es que volverá a subir. 
España e Italia son los mayores importadores de tablones de madera latifoliada en Europa (el $20 \%$ y el $13 \%$ de la importación europea, respectivamente).

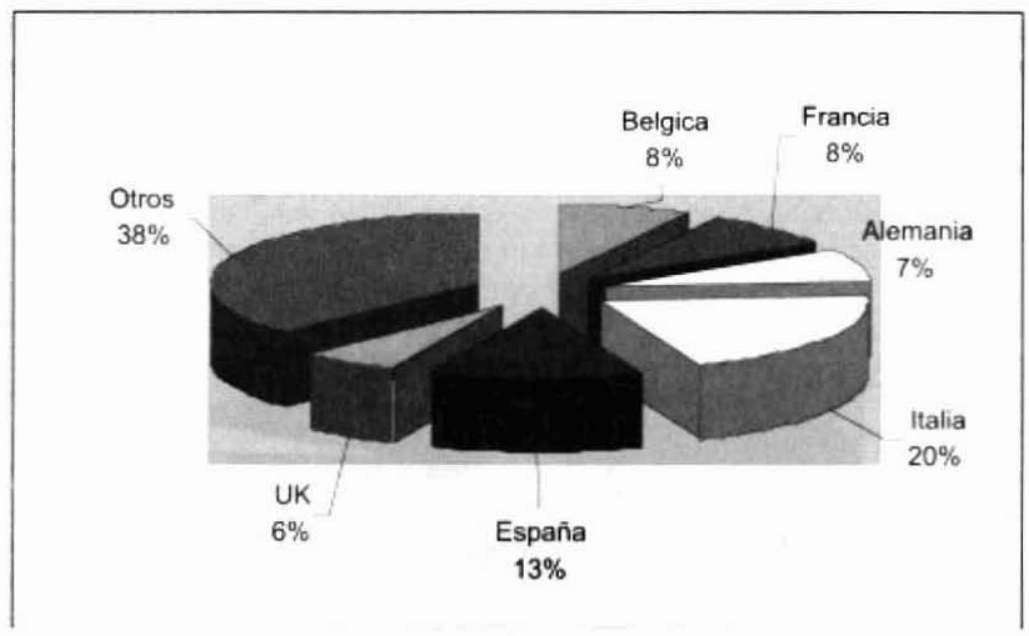

(Fuente: FAO, 2000)

Figura $N^{0} 1$

MAYORES PAISES EUROPEOS IMPORTADORES DE TABLONES DE MADERA LATIFOLIADA

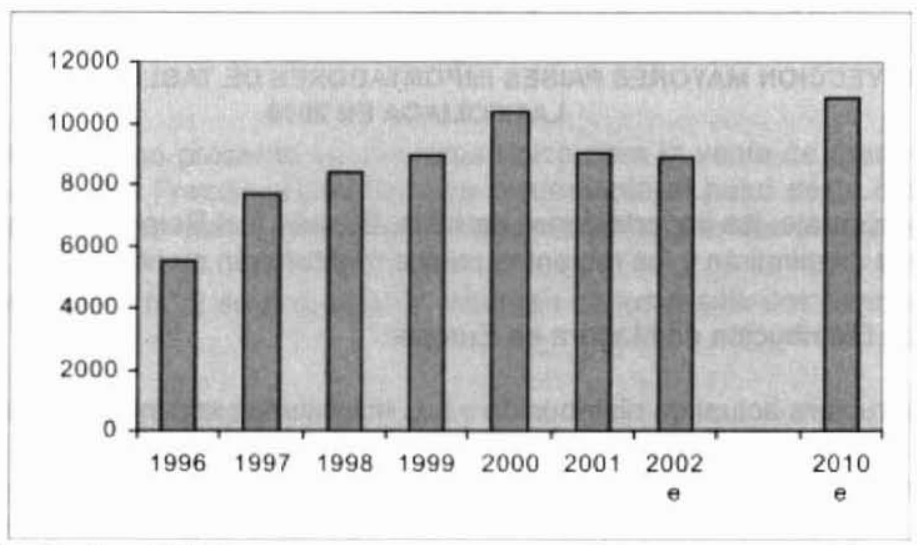

(Fuente: Gardino, 2003)

Figura $\mathrm{N}^{\circ} 2$

PREVISION IMPORTACIONES DE TABLONES DE MADERA LATIFOLIADA EN EUROPA

$$
\left(m^{3} * 10^{3}\right)
$$


Alemania es un pais importador de menores dimensiones, que usa buenas cantidades de haya y muchos tableros alistonados.

Los paises que actualmente importan se mantendrán como los mayores importadores y, en algunos casos, su importancia relativa aumentará ulteriormente.

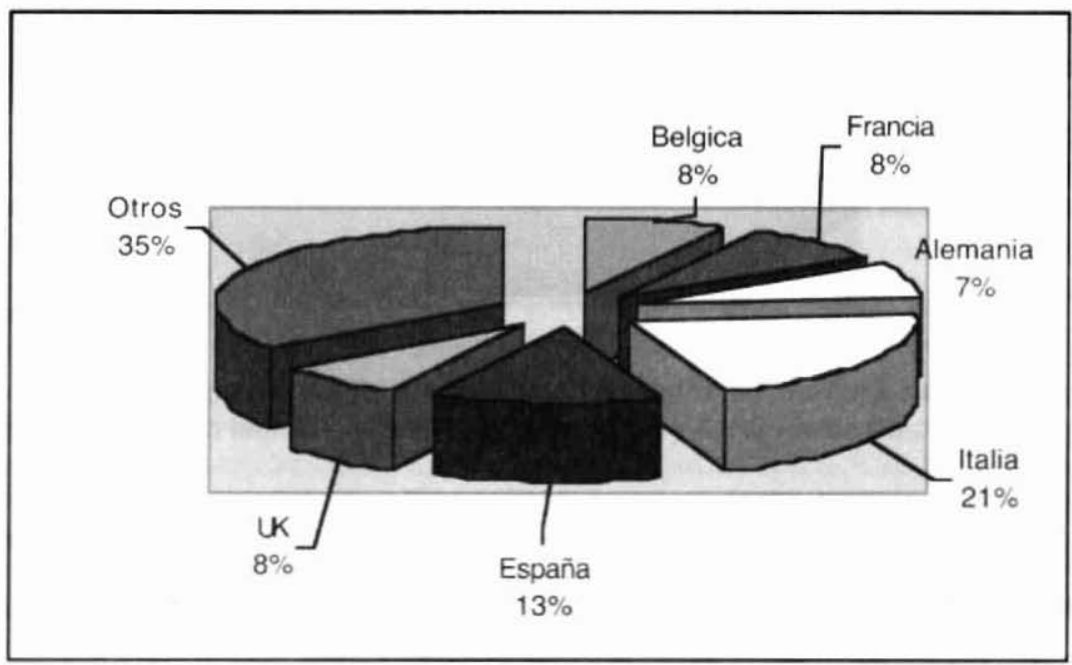

(Fuente Gardino, 2003)

Figura $\mathrm{N}^{\circ} 3$

PROYECCION MAYORES PAISES IMPORTADORES DE TABLONES DE MADERA LATIFOLIADA EN 2010

En porcentaje, las importaciones de Italia, España y el Reino Unido aumentarán, las de Alemania disminuirán y los restantes paises mantendrán su nivel.

- El Sistema de Distribución de Madera en Europa $N^{\circ} 4$.

La estructura actual de distribución y sus magnitudes son indicadas en la Figura 


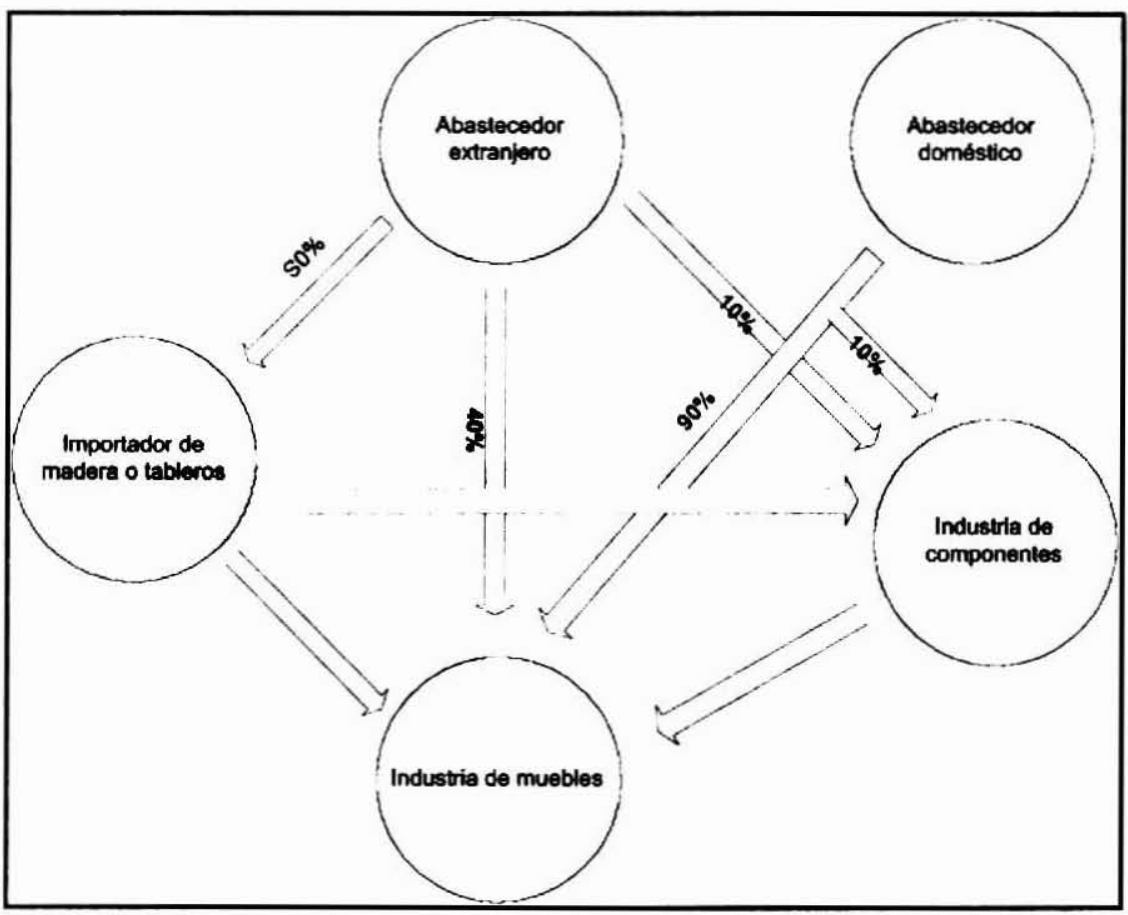

Figura $\mathrm{N}^{\circ} 4$

CANALES DE DISTRIBUCION EN EUROPA, MADERAS Y TABLEROS

En la figura se presenta un esquema típico para la venta de madera aserrada y tableros en Italia. En Francia, Gran Bretaña o Alemania el peso de la industria de los componentes es mucho menor, mientras es mayor el de las grandes fábricas de muebles.

\section{Europa.}

En Apéndice $\mathrm{N}^{\circ} 2$ se presenta un resumen de los resultados para el mercado de

\section{ANALISIS Y CONCLUSIONES} Europa.

El estudio da una clara impresión del potencial de mercado de Estados Unidos y de

La madera de canelo, para ser utilizada principalmente en muebles y molduras especiales aprovechando sus buenas características estéticas y precios, perfectamente puede ser colocada en forma competitiva en el mercado internacional, quizás con más facilidad en Estados Unidos de Norteamérica que en Europa. 
Ambas regiones son grandes mercados para las maderas latifoliadas. El potencial es muy grande, pero requiere productos muy especificos y a un precio competitivo, con dos o tres especies que ya tienen buena aceptación de los usuarios.

La base del éxito en el mercado estará en las entregas oportunas y en el envió de sólo las mejores calidades (dejando para una etapa posterior otras calidades). Se requiere de una gran acción de promoción, más allá de la que pudiera realizar cada empresa individual. La asociatividad de oferentes parece importante como una acción de lograr mejor posición competitiva. Las actividades de investigación aplicada deben orientarse a generar una oferta sostenible de materia prima de calidad, optimizando los procesos de transformación industrial y de manejo del bosque.

Las principales conclusiones y recomendaciones del estudio de mercado externo para madera de canelo se presentan a continuación, primero las relativas a Estados Unidos y, luego, las que se refieren a Europa.

\section{Mercado de Estados Unidos}

Estados Unidos es el mayor productor y consumidor de productos de madera en el mundo. También es el mayor importador y el segundo mayor exportador de productos forestales, incluyendo madera aserrada.

Existen buenas oportunidades de colocación de madera y productos de madera de canelo en EEUU.

California es la cuarta mayor economia del mundo y representa el mercado más grande para productos genéricos, mientras que industrias como las de gabinetes y muebles establecidas en Carolina del Norte podrian ofrecer nichos más específicos para partes y piezas elaboradas con precios más altos.

Los productos más deseados son la madera aserrada secada en hornos con un contenido de humedad entre 8 y $10 \%$, ligeramente cepillada, con espesores, anchos y largos variables. También se busca el "blank" apto para la fabricación de molduras. El contenido de humedad debe ser entre 8 y $10 \%$, nunca más de $12 \%$. Por último, se constató interés por tablero contrachapado de diversos espesores, calidad C o CC, con una o dos caras lijadas. También hay nichos de fuerte demanda para productos especiales, como marcos para pizarrón, puertas de seguridad infantil, piezas torneadas, tarugos, etc.

Se determinó que, en términos de las reglas de la National Hardwood Lumber Association (NHLA), las calidades más deseables para madera aserrada son FAS (una calidad en gran medida libre de defectos), y 1 Común y 2 Común (que aceptan ciertos defectos). Los embarques se podrian hacer incluyendo volúmenes mezclados de las tres calidades, siempre y cuando la participación de las dos mejores no baje de una proporción mínima.

Inicialmente, los distribuidores mayoristas representarian el principal sector comprador de productos sólidos de madera. Una vez establecidos los productos en el 
mercado, podria considerarse la venta directa a establecimientos minoristas, como por ejemplo las cadenas Home Depot y Kmart.

Numerosos importadores y distribuidores indicaron la necesidad de entregar la madera certificada ambientalmente por el Forest Stewardship Council (FSC) o equivalente.

El canelo tendria que competir con maderas duras (latifoliadas) nacionales e importadas de menor precio relativo, como el aliso, haya europea, abedul, acer, álamo, falcata y oukomé.

El rango de precios varia para diferentes categorias y calidades de productos. $A$ modo referencial, el precio para madera aserrada se estimó en US\$1,50-2,00 por pie maderero calidad FAS puesto en el patio de acopio del importador. Para "blanks" destinados a la confección de molduras decorativas, el precio sería de US\$1,80-2,20 el pie maderero FAS, y para "blanks" destinados a la confección de molduras pintadas (con y sin finger-joint) el precio sería de US\$ 1 - 1,20 el pie maderero de calidad indeterminada pero sin defectos visibles. El tablero contrachapado para revestimiento interior y uso estructural/decorativo en gabinetes y muebles, estimó en US\$2,30 a 2,60 el pie cuadrado de $1 / 4$ " clase C.

El costo de transporte maritimo es un factor critico que incide fuertemente en la posibilidad de entregar un producto a precios competitivos. Este servicio desde puerto en Concepción a Long Beach, Los Ángeles se estima en US\$ 120 por $\mathrm{m}^{3}$ en contenedor y USS 65 por $\mathrm{m}^{3}$ en paquetes («break bulk packages»). Las comisiones de los importadores, comúnmente, varían entre 3 y $6 \%$ calculadas sobre el precio FOB o CIF dependiendo de la competitividad del producto, monto vendido, potencial de ventas a futuro, etc. El precio de venta de los distribuidores es de $4-6 \%$ sobre el costo de compra puesto patio.

La madera de Chile entra libre de aranceles de aduana a Estados Unidos.

\section{Mercado Europeo}

Europa es un gran importador de maderas duras y se estima que presentará una demanda creciente para los próximos años. Los países más prometedores son los analizados: Alemania, Italia y España. Hay otros países que pueden tener un futuro potencial, como Portugal, Francia y el Reino Unido.

Italianos y españoles, que hacen negocios forestales con Chile, están bastante dispuestos a hacer pruebas de compras de canelo.

Los sectores con mayor interés para canelo son las empresas productoras de muebles, valorando principalmente su apariencia. También constituye un sector relevante el de los distribuidores. Para pisos, utensilios, molduras especiales hay dudas, por lo liviano de la madera y su poca dureza. El sector molduras es interesante, siempre y cuando se asegure una madera dimensionalmente estable y largos de 2,5 metros y más. La industria europea de los tableros busca constantemente tableros de bajo peso, aspecto importante de explorar 
con canelo. También, aunque más pequeño, se encuentra el mercado para tableros enlistonados, sobre todo en Alemania.

En el corto plazo, el producto más vendible es la madera aserrada cepillada y seca.

El color de la madera de canelo tiene buena aceptación, con la exigencia que debe ser homogéneo. En caso contrario, la recomendación es vaporizar o clasificar la madera por color.

Las empresas de distribución (importadores, almacenes madereros, agentes de venta) se mostraron cautas; hay algún interés por el canelo, pero hay preocupación por la distancia de Chile y por la necesidad de promocionar una especie maderera que es enteramente desconocida.

Las medidas usadas por los fabricantes de muebles son muy variadas. Todos los espesores son usados, especialmente los espesores delgados, como los de $25 \mathrm{~mm}$ o 32 $\mathrm{mm}$. Respecto de los largos, a menudo toleran buenos porcentajes de mercancia corta. Por el contrario, muy pocas empresas aceptan madera con uniones dentadas. En general, las medidas usadas por los fabricantes de sillas son mucho más gruesas (40-50-60 mm). Los fabricantes de escaleras, usualmente, piden espesores de $40 \mathrm{~mm}$ y compran casi toda la mercancia empalmada y encolada.

Casi todos adquieren sólo madera seca en horno, generalmente con contenido de humedad entre 8 y 10 por ciento.

Los canales de distribución cambian según el país, el sector en el cual se venda y el producto. Es importante conocer y respetar los canales de distribución. Para canelo, se estima como lo más conveniente las dos opciones siguientes: a) Importadores especializados en madera latifoliada destinada a las fábricas de muebles y b) Tableros enlistonados y componentes directos a las fabricas de muebles.

En Italia, en general, no hay interés respecto a la certificación. En España hay más interés, pero la certificación no se ve como una necesidad. En Alemania hay una atención mayor, pero también en este pais la certificación no es una condición absoluta. Si el procedimiento de certificación no es demasiado complejo, será preferible certificar a fin de facilitar las ventas.

Se recomienda clasificar la madera de canelo según las reglas de la National Hardwood Lumber Association (NHLA) de los EEUU y dentro de éstas las mejores calidades.

Los precios de referencia para el canelo son los de la haya. Se ha indicado que, para una fase de introducción, el precio estimado oscilará entre los $€ 210$ y los $€ 280$ por metro cúbico libre cliente final para madera aserrada seca. Se recuerda que la haya se vende en medidas muy apreciadas por el mercado, en gruesos y anchos ideales (por ejemplo 47 o $57 \times 150 / 160 \mathrm{~mm}$ y más, o semejantes). 
Los fabricantes de muebles usan maderas económicas (haya) y también muy caras (cerezo, arce, etc). En este sector el posible precio de venta está basado en el valor de la haya, $€ 250-400$ por metro cúbico (tablones secos o verdes libre cliente). Ciertamente, los fabricantes de muebles pueden pagar precios mucho más altos. La motivación de compra no está influenciada mayormente por el factor precio sino, sobre todo, por factores estéticos, por lo cual si un fabricante de muebles decidiese hacer una serie de muebles de canelo, podria pagar por esta madera un precio incluso notablemente superior al de la haya.

El costo del transporte de Chile a Europa es de $€ 40 / 45 / \mathrm{m} 3$ y hasta el cliente final es de $€ 70 / 75 / \mathrm{m} 3$, aproximadamente.

No se ha comprobado aranceles específicos o barreras para la venta de madera de Chile a Europa.

\section{REFERENCIAS}

FAO, 2000. Anuario de Productos Forestales. Roma, Italia, 445 páginas.

FAO, 2002. Anuario de Productos Forestales, Roma, Italia, 458 páginas.

Gardino, P., 2003. Posibilidad de Venta del Canelo en Europa. Estudio subcontratado por INFOR, Chile. Génova, Junio 2003. 168 páginas. Extracto publicado en INFOR, Informe Técnico 167, 2004.

Casasempere, A., Cartwrigh D., 2003. Estudio de Mercado en EEUU para Madera de Canelo, 2003. Grypshon Resource Consultants Ltd. Estudio Subcontrado por el Instituto Forestal. Vancouver, Canada, 2003. 188 páginas. Extracto publicado en INFOR, Informe Técnico 167, 2004. 
PRINCIPALES RESULTADOS DE LAS VISITAS A EMPRESAS EN EEUU (Junio 2003)

\begin{tabular}{|c|c|c|c|c|c|c|}
\hline Producto & Calined & Dimeneitones & Otren & Uno Final & Rango do Procio (UVS) & Otres Comentimitos \\
\hline Wedera aserreda & 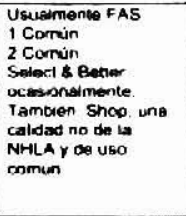 & 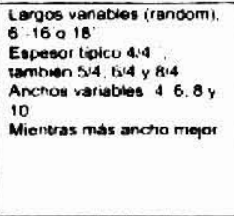 & 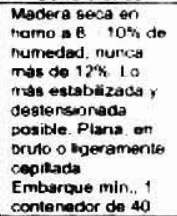 & 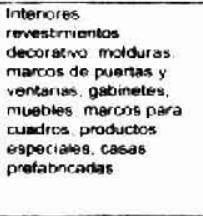 & 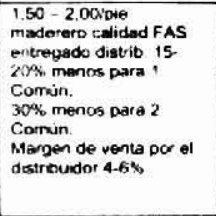 & 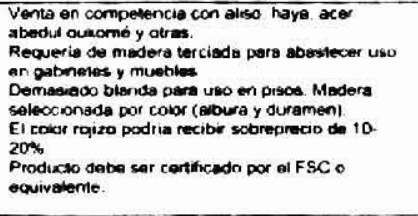 \\
\hline 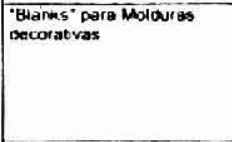 & FAS & 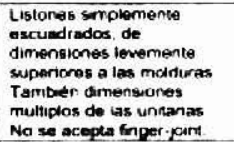 & $\begin{array}{l}\text { Meder a seca en } \\
\text { homo de } 8 \text { a } 10 \% \\
\text { de humedad. } \\
\text { nunca mas de } \\
\text { i2\% Otas } \\
\text { smulares a madera } \\
\text { asarrada }\end{array}$ & $\begin{array}{l}\text { Uso decoraemo intenar } \\
\text { on paredes, marcos y } \\
\text { itstoras pera gabinetes } \\
\text { y estanies }\end{array}$ & $\begin{array}{l}1.80-2.000 \text { ne mad } \\
\text { Entogado distrib }\end{array}$ & $\begin{array}{l}\text { Producto debe ser centikcado por el FSC } 0 \\
\text { equivastemle }\end{array}$ \\
\hline $\begin{array}{l}\text { 'Blanks' par a molduras } \\
\text { pentassass }\end{array}$ & $\begin{array}{l}1 \text { y } 2 \text { Comun. usual } \\
\text { Otra nferwites } \\
\text { lamber }\end{array}$ & $\begin{array}{l}\text { Listanes smplemienter } \\
\text { escuadrados, de } \\
\text { dimensuones levemente } \\
\text { superiores a las molduras. } \\
\text { Tamben, dnensiones } \\
\text { multiplos de las untaras } \\
\text { Puede ser mper-pans. }\end{array}$ & $\begin{array}{l}\text { Madera soca en } \\
\text { nomo de } 8 \text { a } 10 \% \\
\text { de humedad. } \\
\text { nunca mbs de } \\
12 \% \text { Otras } \\
\text { simianes a madera } \\
\text { aserrads }\end{array}$ & $\begin{array}{l}\text { Uso pontado intenar en } \\
\text { paredes, marcos, } \\
\text { listoress para gabiretes } \\
\text { y efetanles. }\end{array}$ & $\begin{array}{l}\text { 1,00-1,20ipue mad } \\
\text { pritaso cualovier } \\
\text { calded sin defertios a ta } \\
\text { vista }\end{array}$ & $\begin{array}{l}\text { Producio debe ser bien dimersionado separado } \\
\text { por collot y cerifícado por al FSC o equavalente. }\end{array}$ \\
\hline Producto & Callowed & Dimenolionosen & Condices & Ueo Final & Rango de Precio (USS) & Otree Comenteriloe \\
\hline Isadera terciada & c & $4 \times 8$ & $\begin{array}{l}\text { Tablero a lo\%, de } \\
\text { rumedad Una } \\
\text { cara tiyada o de } \\
\text { acuerdo a las } \\
\text { reptas de WHLA. }\end{array}$ & $\begin{array}{l}\text { Revestitremos int, } \\
\text { gabinetes, muebies }\end{array}$ & 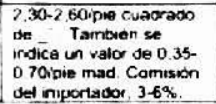 & 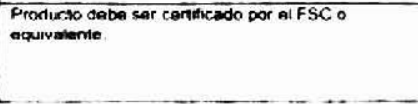 \\
\hline 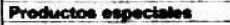 & & & & & & \\
\hline Marcus para pizarión & $\begin{array}{l}\text { Madera libre de } \\
\text { detectos y sin firmer. } \\
\text { pant }\end{array}$ & $\begin{array}{l}\text { Listunes de } 1.4 \text { de lavo } \\
\text { con perntes especinicos }\end{array}$ & $\begin{array}{l}\text { Madera secas en } \\
\text { nomo a 8-10\%, de } \\
\text { humnedad, nurcal } \\
\text { mas de } 10 \%\end{array}$ & $\begin{array}{l}\text { Marcos vara picarrones } \\
\text { de ohona }\end{array}$ & $\begin{array}{l}500.510 . \mathrm{m} \text { FOB puento } \\
\text { chileno }\end{array}$ & $\begin{array}{l}\text { Se requieren para comenzar dos comenededres } \\
\text { lae } 40 \text { pees I por mes Compracor OLM Nordisk } \\
\text { inc }\end{array}$ \\
\hline Puertas de soguridad & FAS & 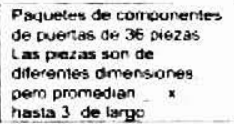 & $\begin{array}{l}\text { Mader a seca en } \\
\text { nomo a E-10\%, de } \\
\text { numbedad nunca } \\
\text { mas de } 10 \%\end{array}$ & $\begin{array}{l}\text { Puertas de seguridad } \\
\text { para controlar el paso } \\
\text { de betbes }\end{array}$ & $\begin{array}{l}650 / \mathrm{m} \text { Cir planta del } \\
\text { tabncame en MT } \\
\text { Sierling KY }\end{array}$ & $\begin{array}{l}\text { Se requiere } f \text { conmeriedor de } 4 \overline{0} \text { cada } 45 \text { dias. } \\
\text { con una capecidad epror de } 6200 \text { pequeses de } \\
\text { componertes }\end{array}$ \\
\hline $\begin{array}{l}\text { Otros Partimberoe } \\
\text {-Transporte" }\end{array}$ & \multirow{2}{*}{\multicolumn{6}{|c|}{ 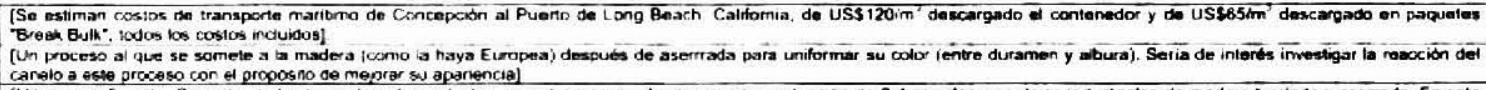 }} \\
\hline -Vaporización". & & & & & & \\
\hline "Demanda Total iniclar" & \multicolumn{6}{|c|}{ 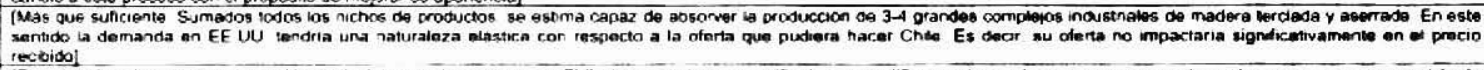 } \\
\hline $\begin{array}{l}\text { "Rolacion con } \\
\text { Olotribuldore" }\end{array}$ & \multicolumn{6}{|c|}{ 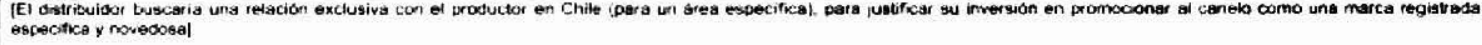 } \\
\hline
\end{tabular}




\section{APENDICE $N^{\circ} 2$}

\section{Principales Resultados de las Visitas a Empresas en Europa}

\begin{tabular}{|c|c|c|c|c|c|c|c|c|}
\hline Alemania & $\begin{array}{l}\text { Especies } \\
\text { compradas } \\
\text { usualmente }\end{array}$ & Color y peso & $\begin{array}{l}\text { Posibilidades de } \\
\text { trabajar el } \\
\text { canelo }\end{array}$ & Opinion global & $\begin{array}{l}\text { Productos comprados } \\
\text { usualmente }\end{array}$ & Competencia & $\begin{array}{l}\text { Interde en } \\
\text { certificacion }\end{array}$ & Precios \\
\hline $\begin{array}{l}\text { Sector } \\
\text { mueble }\end{array}$ & $\begin{array}{l}\text { Haya, red } \\
\text { aider maple. } \\
\text { abedu }\end{array}$ & $\begin{array}{l}\text { El color es considerado } \\
\text { positivo, aunque quizás } \\
\text { demasiado rojo. El peso lo } \\
\text { consideran algo ligero. }\end{array}$ & $\begin{array}{l}\text { No se han recibido } \\
\text { comentanos }\end{array}$ & $\begin{array}{l}\text { Positiva Están } \\
\text { dispuestos a realizar } \\
\text { peque in as } \quad 0 \\
\text { medianas compras } \\
\text { con canelo }\end{array}$ & $\begin{array}{l}\text { Tabiones. tableros alistonados }(18 / 25 \\
\times 700 / 1600 \times 2300 / 2500 \text { y } 18 / 25 / 50 \times \\
1600 \times 4000 \mathrm{~mm}) \text { y productos semi } \\
\text { acabados }\end{array}$ & $\begin{array}{l}\text { haya y en } \\
\text { medida menor } \\
\text { con el red alder } \\
\text { yet tulipier }\end{array}$ & Si.FSC & $\begin{array}{l}E 570 \mathrm{~m}^{3} \text { (red } \\
\text { adder } \\
\text { empalmados) } \\
\in 8004900 \text { (iston } \\
\text { enlero) y } E \\
1000 / \mathrm{m}^{3} \text { (haya) }\end{array}$ \\
\hline $\begin{array}{l}\text { Sector } \\
\text { slllas }\end{array}$ & $\begin{array}{l}\text { Haya, roole, } \\
\text { maple cerezo }\end{array}$ & $\begin{array}{l}\text { El color y el peso son } \\
\text { considerados posativas }\end{array}$ & Juicio postivo & Juicio posituo & & & $\begin{array}{l}\text { No hay } \\
\text { nteres }\end{array}$ & \\
\hline $\begin{array}{l}\text { Pisos de } \\
\text { madera }\end{array}$ & $\begin{array}{l}\text { Roble. } \\
\text { abedul, haya } \\
\text { especies } \\
\text { tropicales }\end{array}$ & $\begin{array}{l}\text { Calor, bueno y peso } \\
\text { Imano }\end{array}$ & Demasiado blando & $\begin{array}{l}\text { Una empresa da } \\
\text { juicio positivo y otra } \\
\text { no }\end{array}$ & $\begin{array}{l}\text { Frisas para parquet, tanma flotante } \\
\text { acabada, chapa. Suelos acabados } 14 \\
\times 122 \times 2500 / 2700 \mathrm{~mm}\end{array}$ & Haya & $\begin{array}{l}\text { Algunos } \\
\text { muestran } \\
\text { interes. }\end{array}$ & \\
\hline Distribuidores & $\begin{array}{l}\text { Haya. roble } \\
\text { abedul y } \\
\text { muchas otras }\end{array}$ & $\begin{array}{l}\text { Color positivo y peso } \\
\text { como el de haya o el } \\
\text { maple }\end{array}$ & $\begin{array}{l}\text { Posibilidad de } \\
\text { comprar mercancia } \\
\text { empalmada } \quad 0 \\
\text { encolada }\end{array}$ & $\begin{array}{l}\text { Disponibilidad a } \\
\text { efectuar una prueba } \\
\text { con esta especie } \\
\text { maderera }\end{array}$ & $\begin{array}{l}\text { Todos los productos, tabiones, sem } \\
\text { acabados, tableros. Se preferirian los } \\
\text { tableros Medidas análogas a Haya: } \\
18 \text { : } 40 \mathrm{~mm} x \text { diferentes anchos y } \\
\text { targos. }\end{array}$ & Haya y maole & $\begin{array}{l}\text { Algunos } \\
\text { muestran } \\
\text { interes. }\end{array}$ & $\begin{array}{ll}\in 250 \text { por } \mathrm{m}^{2} \\
\text { (haya } & \text { no } \\
\text { canteados) } & \end{array}$ \\
\hline
\end{tabular}




\begin{tabular}{|c|c|c|c|c|c|c|c|c|}
\hline Eapanta & $\begin{array}{c}\text { Eepecies compradas } \\
\text { usualmentu }\end{array}$ & Color y po:so & Poelitidedes do & Opiailon globel & $\begin{array}{l}\text { Wereancia compreda } \\
\text { usualmente }\end{array}$ & Competencis & $\begin{array}{l}\text { Intaris en } \\
\text { centilleacio } \\
n\end{array}$ & Precios \\
\hline Distribuidores & $\begin{array}{l}\text { Todo tpo de producto } \\
\text { maderero. }\end{array}$ & $\begin{array}{l}\text { Cotor oscuro causa } \\
\text { problemes y el peso } \\
\text { demasiado liviano }\end{array}$ & $\begin{array}{l}\text { Parece buena. pero } \\
\text { aguen sugiere que } \\
\text { quizts se tuerza }\end{array}$ & $\begin{array}{l}\text { En gerieral no es } \\
\text { demasiado positivo, } \\
\text { aunque no sea } \\
\text { enturamente } \\
\text { negativo. }\end{array}$ & $\begin{array}{l}\text { Tableros alstonados } \\
\text { B/25/30/4a,50 y hasta los } \\
100 \mathrm{~mm} \text {. Largos sobre } \\
\text { los } 2,5 \mathrm{~m} \text {. }\end{array}$ & Pitano y haya. & Moderado & $\begin{array}{l}€ 1700 m^{3} \\
\text { (alistonados } \\
\text { haya) }\end{array}$ \\
\hline $\begin{array}{l}\text { Mengos pare } \\
\text { utensilios }\end{array}$ & $\begin{array}{l}\text { Haya eucaliptos } \\
\text { guatambu tresno }\end{array}$ & $\begin{array}{l}\text { Color borito y peso } \\
\text { invano. }\end{array}$ & $\begin{array}{l}\text { Debe ser ductli al } \\
\text { torneo. }\end{array}$ & $\begin{array}{l}\text { Posiblemente } \\
\text { negativo, por su } \\
\text { baja densidad }\end{array}$ & $\begin{array}{l}\text { Elementos con medidas } \\
\text { fjas } \\
47 \times 47 \times 8001900 / 1000 \text { y } \\
42 \times 42 \times 80090011000 / 12 \\
00 \mathrm{~mm} \text {. brutos }\end{array}$ & Eucaliptos & No & $\begin{array}{l}+250: \mathrm{m}^{2} \\
\text { (eucalpto) }\end{array}$ \\
\hline $\begin{array}{l}\text { Wuebles y puertas } \\
\text { pera muebles }\end{array}$ & $\begin{array}{l}\text { Haya, roble, castaño, } \\
\text { pno, iroko, acacia. } \\
\text { maple, cerezo }\end{array}$ & $\begin{array}{l}\text { Color negatro (oscuro } \\
\text { y vetas negras) y peso } \\
\text { wiano. }\end{array}$ & $\begin{array}{l}\text { Hay reacciones, } \\
\text { mayormente } \\
\text { positvas }\end{array}$ & $\begin{array}{l}\text { En general es } \\
\text { bastante negatva } \\
\text { La moda pide } \\
\text { maderas claras }\end{array}$ & $\begin{array}{l}\text { En general tablones } \\
\text { brutos secos Largos } \\
\text { imitados. } 750-1500 \mathrm{~mm}\end{array}$ & $\begin{array}{l}\text { Cerezo, haya, } \\
\text { abedul roole. } \\
\text { bulipier. }\end{array}$ & $\begin{array}{l}\text { Si. señalan } \\
\text { que es } \\
\text { interesante. }\end{array}$ & $\begin{array}{l}\epsilon 630 / m^{3} \\
\text { (tablones haya) }\end{array}$ \\
\hline Fabricantes do sllas & $\begin{array}{l}\text { Haya, un pocos de roole. } \\
\text { pino. }\end{array}$ & $\begin{array}{l}\text { Color demaseado } \\
\text { oscuro y peso darece } \\
\text { lgero }\end{array}$ & $\begin{array}{l}\text { Si. por pequerias } \\
\text { cantidades para } \\
\text { hacer elementos } \\
\text { laterales de las } \\
\text { sillas. }\end{array}$ & $\begin{array}{l}\text { Dudas Se teme } \\
\text { que no ressta. }\end{array}$ & $\begin{array}{l}\text { Compran elementos } \\
\text { acavacos para sillas } \\
\text { Tableros para mesas de } \\
80 \times 160.90 \times 90,90 \times 200 \\
\mathrm{~cm}\end{array}$ & Haya y maple & $\begin{array}{l}\text { Elevado } \\
\text { interes }\end{array}$ & \\
\hline Pisos de madera & $\begin{array}{l}\text { Haya. rodie. patoba y } \\
\text { otras }\end{array}$ & $\begin{array}{l}\text { Cator bonito pero } \\
\text { oscuro. Peso, nicio } \\
\text { posivwo }\end{array}$ & Poca disponibidad & $\begin{array}{l}\text { Algunos b } \\
\text { consideran } \\
\text { adecuado. }\end{array}$ & $\begin{array}{l}\text { Chapa y tablones } \\
27: 30 \times 60180 \times 350-500 \\
520.1030 \mathrm{~mm}\end{array}$ & Conezo y roble & $\begin{array}{l}\text { Lo } \\
\text { consideran } \\
\text { importante }\end{array}$ & $\begin{array}{l}\in 3000 \\
\text { (parquel roble) }\end{array}$ \\
\hline
\end{tabular}




\begin{tabular}{|c|c|c|c|c|c|c|c|c|}
\hline Vtalla & $\begin{array}{l}\text { Especies } \\
\text { compradas } \\
\text { usualmente }\end{array}$ & Color y peso & $\begin{array}{l}\text { Posibilidades do } \\
\text { trabojar el canelo }\end{array}$ & Opinión global & $\begin{array}{l}\text { Hereancis compracta } \\
\text { usualunente }\end{array}$ & Compenencia & Interits en & Precios \\
\hline $\begin{array}{l}\text { Articulos caseros y } \\
\text { mangos de madera }\end{array}$ & Maya & $\begin{array}{l}\text { Coicr positivo y peso } \\
\text { aceplable }\end{array}$ & $\begin{array}{l}\text { Jucco positiva. Hay } \\
\text { posibildad si el } \\
\text { procio } \\
\text { conveniente. }\end{array}$ & Buena & $\begin{array}{l}\text { Tabiones y sem } \\
\text { acabados con medidas } \\
\text { has. Gruesos } 50606 \mathrm{~mm} \\
\text { largos de } 2.50 \mathrm{~m} \text { en } \\
\text { adalante. }\end{array}$ & $\begin{array}{l}\text { Maderas rojas } \\
\text { ancanas. } \\
\text { ramin, haya. }\end{array}$ & No. & \\
\hline Escaleras de madera & Haya abeto & $\begin{array}{l}\text { Color demasado oscuro } \\
\text { y rojo y peso positivo. }\end{array}$ & $\begin{array}{l}\text { Hay opiniones } \\
\text { posibvas y } \\
\text { negatrvas. }\end{array}$ & Bastante negativa & $\begin{array}{l}\text { Acabados empalmados } \\
\text { y encolados. } \\
40-42 \times 650-1000-1300 \\
\times 700-1000-1700 \mathrm{~mm}\end{array}$ & $\begin{array}{l}\text { Haya, corezo y } \\
\text { abeto }\end{array}$ & No. & $€ 450$ (haya) \\
\hline Pisot de madera & $\begin{array}{l}\text { Roble, corezo. } \\
\text { haya, tresno. } \\
\text { toca, doussie } \\
\text { afrormosta }\end{array}$ & $\begin{array}{l}\text { Calor, puicio positivo, pero } \\
\text { al peso no va bien. }\end{array}$ & No hay posibidad. & Negativa & $\begin{array}{l}\text { Tabilas para parquet } \\
\text { semi acabadas y no } \\
\text { secadas. } \\
10-14-22 \times 50-60-70 \times \\
150-200-300-350 \mathrm{~mm} \text {. }\end{array}$ & Haya y roble & No. & \\
\hline $\begin{array}{l}\text { Inebles, puertas y } \\
\text { partes }\end{array}$ & $\begin{array}{l}\text { Haya. roble, } \\
\text { nogal. fresno. } \\
\text { cerezo, alamo. } \\
\text { tulpier. red } \\
\text { alder. castaño }\end{array}$ & $\begin{array}{l}\text { Color interesanle y peso } \\
\text { positwo. }\end{array}$ & Parece buena & $\begin{array}{l}\text { En general es } \\
\text { positiva }\end{array}$ & $\begin{array}{l}\text { Tabiones y serni } \\
\text { acabados. } \\
4 / 4 \text { e } 5 / 4^{\circ} \text {. Anchos } \\
\text { sobre } 25^{\circ} \text {. } \\
\text { Largos Desde } 350-400 \\
\text { mm que de } 1900 \mathrm{~mm} \text {. }\end{array}$ & $\begin{array}{l}\text { Ramin, haya } \\
\text { vaporizada. } \\
\text { tulpier }\end{array}$ & $\begin{array}{l}\text { Hay inleres. } \\
\text { pero no hay } \\
\text { demanda. }\end{array}$ & $\begin{array}{l}\in 350400 \\
\text { (taplones } \\
\text { naya). } \\
\in 450500 \\
\text { (toplones } \\
\text { tulpier) }\end{array}$ \\
\hline Fabrieantes do sillas & $\begin{array}{l}\text { Haya, roble y } \\
\text { pino }\end{array}$ & $\begin{array}{l}\text { Color oscuro pero bien y } \\
\text { peso liviano }\end{array}$ & $\begin{array}{l}\text { Es importante la } \\
\text { resistencia y la } \\
\text { Dosibilidad de } \\
\text { encorvar los } \\
\text { elementos }\end{array}$ & $\begin{array}{l}\text { Inadecuado por el } \\
\text { color y la baja } \\
\text { resistencia }\end{array}$ & $\begin{array}{l}\text { Sern acabados con } \\
\text { medidas fias y } \\
\text { pequerias cantidades de } \\
\text { tablones (25-32-38-50y } \\
60 \mathrm{~mm} \text { ). } \\
\text { Largos } 400-450-1100 \\
\text { mm }\end{array}$ & Haya & No & $\begin{array}{l}\in \text { Gap-700 } \\
\text { (haya) }\end{array}$ \\
\hline Distribuidores & $\begin{array}{l}\text { Todas las } \\
\text { especies } \\
\text { madereras }\end{array}$ & $\begin{array}{l}\text { Juicio positivo y peso } \\
\text { iviano. }\end{array}$ & $\begin{array}{l}\text { Si, aunque las } \\
\text { muestran parecen } \\
\text { bastante nermosas. }\end{array}$ & $\begin{array}{l}\text { Utizzable en } \\
\text { puertas si hay } \\
\text { largos adecuados. }\end{array}$ & $\begin{array}{l}\text { En general tablones } \\
\text { brutos. Grueso de } 1^{\circ} \text { a } \\
2 \text {. } \\
\text { Largo desde los } 2,50 \mathrm{~m}\end{array}$ & Haya. bahia & No. & \\
\hline
\end{tabular}


